\title{
DIGITAL BUILT ENVIRONMENT MATURITY MODEL: DIGITAL TWINS ADVANCING SMART INFRASTRUCTURE ASSET MANAGEMENT
}

\author{
Dejan Papic ${ }^{1}$, and Tomo Cerovsek ${ }^{2}$ \\ ${ }^{1}$ Bentley Systems, London, UK \\ ${ }^{2}$ University of Ljubljana, Ljubljana, Slovenia
}

\begin{abstract}
Re-definition of environmental, social, and economic outcomes is constantly pushing the infrastructure industry towards advanced digitalisation. Increasing amount of information on the use, behaviour and performance of infrastructure assets enables better decision making and asset value management. Digitalisation enables more effective utilisation of existing assets, better design, selection, and delivery of new assets. Asset data can contribute to improving the value of an asset in its life-time, a citizens' quality of life, and economic growth. Asset data is key for smart infrastructure management. Process and technology advancements enable the transformation of physical infrastructure into a smart infrastructure (digitally represented by digital twin) which may store the historical and real-time status of a physical counterpart. This paper targets methods, processes, and technologies which may be used to better capture, organise, analyse and understand the status and behaviour of infrastructure assets. Presented smart asset management maturity model will enable asset owners to introduce new methods of monitoring and decision making that may lead to the innovative smart infrastructure asset management.
\end{abstract}

\section{Introduction}

The speed of innovation is increasing. Technological advancements, which have happened in the last few decades, have enabled a comprehensive change in the way business is done. Digitalisation is changing the roles people play in their organisations. Redefined economic, environmental, and social outcomes have increased the need for the adoption of digital ways of working. Big investments in the infrastructure networks that took place in developed countries post 1950s have caused the returns on investment of newbuilt infrastructures to steadily fall. The infrastructure networks built in the second part of the 20th century are aging and causing huge costs, e.g. in 2014 the USA spent $57 \%$ of the budget dedicated to infrastructure on operations and maintenance (Popper and Gates, 2016).

The above mentioned facts introduced several challenges within three interconnected environments:

- socio-economic

- technological (cyber-physical)

- organisational
Socio-economic environment. The financial crisis of 2007-08 and the ensuing recession, have caused shrinkage of infrastructure asset management budgets (Brumby and Verhoeven, 2010). The extreme climate changes have prodded World leaders to establish stricter laws and regulations to decrease the effect of our way of living on the natural environment. The rise in population, their standard of living, and organisational competition are increasing the need for quality and throughput of infrastructure assets that are needed to provide adequate services to end-users.

Technological (cyber-physical) environment. Digital technology and process advancements, with re-defined outcomes of the 21 st century, gnerate the need for improvements in the way built assets are managed. One of the most important realisations has been that not all problems in infrastructure can be solved by building new infrastructure assets, but rather the efficiency of existing infrastructure assets must be improved. A comprehensive programme was started in the UK, in 2011, when the Government Construction Strategy (Cabinet office, 2011) was published.

Organisational environment. In order to improve the outcomes our infrastructure assets provide us, asset management organisations need to undergo a comprehensive change programme. The final goal of the change programme should be an agile, ever optimising - SMART organisation, capable of identifying needs and then implementing and using the latest developments which will help improve social, environmental, and economic outcomes which define their competitive advantage. Slow development of digital capabilities within infrastructure asset management organisations leaves a lot of room for improvement, and subsequently the efficiencies and improved outcomes these organisations can achieve through better, smarter management of their assets.

What is the way forward for 'smart asset management' organisations?

The increasing awareness of the benefits that new technologies bring has caused the increasing adoption of advanced digital technologies by organisations. However, these are often partial solutions and do not bring the desired benefits and potential comprehensive capability improvements that strategically aligned digital organisations are trying to achieve. 
Therefore, these organisations still have a long way to go before they start reaping the significant benefits digitalisation brings. Digital alignment and constant change synchronisation can drive change and advance project performance (Bentley, 2018).

Adopting a capability maturity model approach for the gradual improvement of digital capabilities has proven to be the right way for organisations in other industries. Undergoing a comprehensive assessment allows the organisations to establish their current level of maturity. By understanding what is required to progress to the next level organisations can then plan how best to achieve it. The gradual progression through levels of maturity allows an organisation to steadily plan and mitigate any risks associated with a single, organisation - wide change.

This paper tries to unveil critical milestones that help the development of advanced methods and procedures to drive organisations to take advantage of digital twins, which are digital replicas of physical world that can drive change and new business models on one hand, increase the capacity, and introduce new sustainable development methods on the other.

This paper follows standard IMRAD structure, starting with research methodology that targets smart asset management, supported by the digital twins.

\section{Methodology}

The main problem addressed in this study is HOW to make asset management smarter? Obviously, the problem translates into digitalisation of a built environment and analysis of socio-technical systems. The problem formulation and analysis directed the research methodology (see Figure 1) that comprised: literature surveys, action research and frame-working.
Literature surveys. Literature surveys included scoping literature reviews which lead to identification of specific engineering genres along with systematic quantitative and qualitative state-of-the-art literature reviews. Special focus was given to genre research which targeted guidelines and specifications that try to classify the level of implementation of digital technologies in organisations or, in broader context, geographic regions or industries for example. Specific sub-genres that were studied in more detail are digital product and process maturity models and accompanying frameworks. The literature and genre research were facilitated by a continuous learning process resulting from action research.

Action research. Action research covered three main iterative phases which identified elements of solutions which were synthesised and tested in the context of applicable systems of systems. The focus on the development process was on key conditions that can enable "digital operations" in asset management organisations. The research methodology provided an appropriate approach for the iterative development of a maturity model, along with frame-working.

Frame-working. The goal was to identify frameworks that would frame as many possible aspects that might affect digitalisation of a built environment. For this purpose several candidate frameworks were shortlisted and tested in practical research work. Zachman's Framework (1987) was found particularly applicable to analyse What, How, When, Who, Where, and Why specific factors are relevant. According to Zachman, it is the integration of the answers to these questions that enables a comprehensive and composite description of complex ideas. There are 6 distinctive steps of the framework: Identification, Definition, Representation, Specification, Configuration and Instantiation.

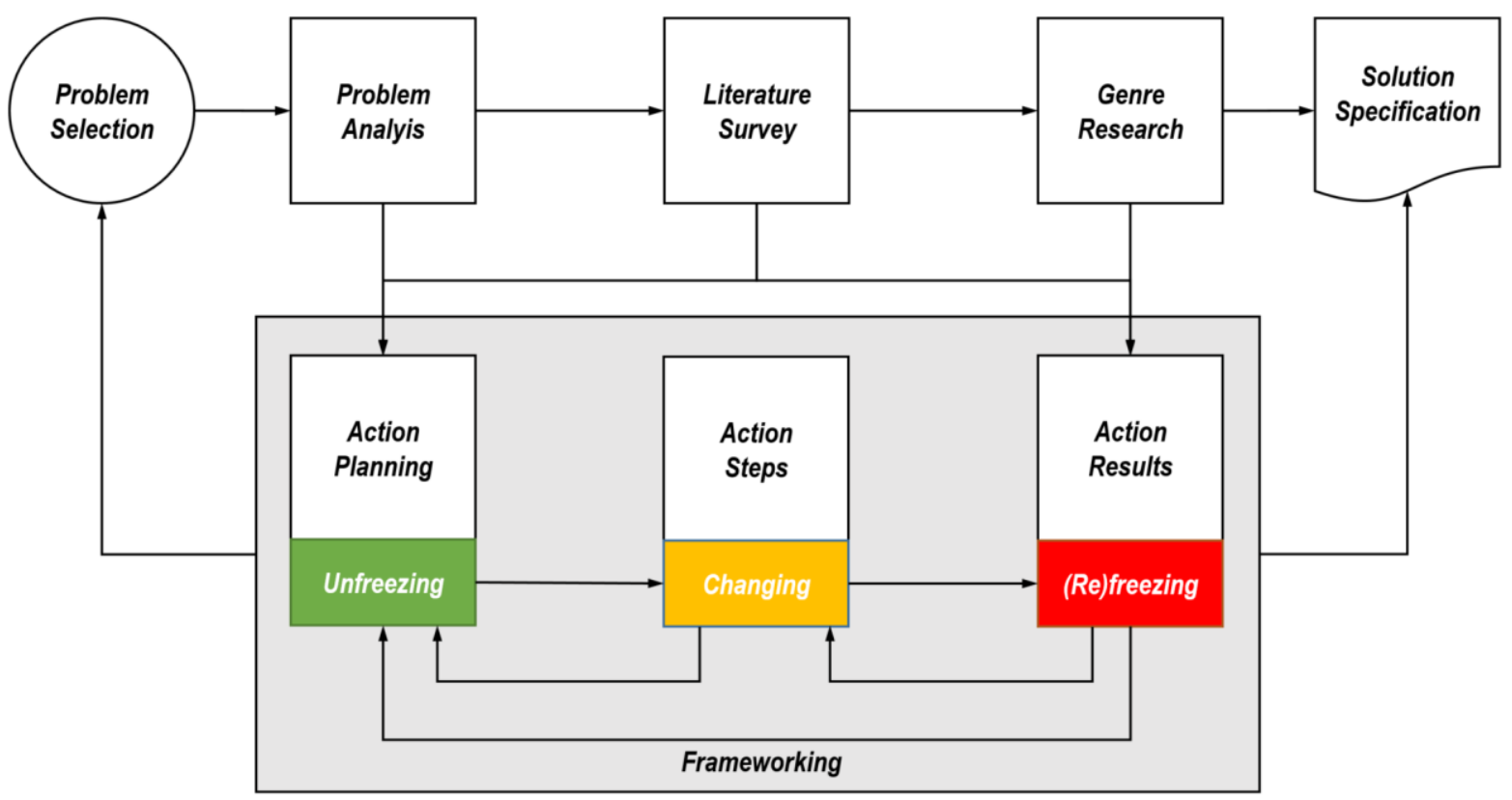

Figure 1: Research methodology: frame-worked action research 


\section{Research on digital capabilities}

In this section, focus is on the background review of Capability Maturity Models (CMM) and applicable frameworks for use in smart asset management. Section 3 is the main input to section 4, which presents the core of developed smart asset management maturity model with digital twins.

Background. As the need for the development of new software began to rise due to popularisation and consumerization of computers, so did the difficulties related to the delivery of software projects. There were only a few best practices that could be used for the increasing number of software implementations.

Due to late delivery or no delivery of the software projects, the US Air Force funded a study at the Software Engineering Institute. To allow the US federal government to assess the capability of its software providers, the Software Engineering Institute produced a brief description of the process maturity framework and a maturity questionnaire (Paulk et al, 1993). With the help of this tool, the software organisation could identify the processes which needed improvement. These two later evolved into the Capability Maturity Model for Software (CMM).

\section{Capability Maturity Models (CMM)}

CMM was followed by the CMMI (Capability Maturity Model Integration) (SEI, 2010), which was looking to integrate many models into one framework. The Capability Maturity Models define five levels which represent an organisation's current capability.

The maturity model can also be used to identify processes which need improvement in order to achieve an organisation's business goals. Over the years, the CMMI has been adopted to many different industries and areas, such as regulatory compliance (O'Kane, Casserly and McCartney, 2015). Typically, a maturity model consists of a number of components (Fraser,
Moultrie and Gregory, 2002): number of levels, description of each level, and description of characteristics expected of an organisation at each level, number of dimensions, description of elements/activities at each dimension, and description of each activity as performed at each maturity level.

An overview of some relevant maturity models in the context of Zachman's framework is presented in the Table 1 below. Notably, most of the maturity models prescribe what is required and rarely elaborate methods, responsibilities and roles, and reasons why a particular maturity must be achieved.

It is also interesting that most of the maturity models do not use the concept of time, though, some wellestablished maturity models do define the period of validity of maturity. An interesting attempt of standardisation of BIM maturity is for example initiated by BSI Kitemark evaluation of BIM Level 2.

\section{Asset management assessment}

ISO 55000 provides a concise definition of asset management (ISO, 2014): 'a coordinated activity of an organisation to realise value from an asset'.

The standardisation of asset management helps the industry in adoption of asset management at a strategic level, focusing on the whole life-cycle of the system of systems of assets, within integrated management system. This offers organisations the opportunity to realise value on a much broader scale than could be achieved by focusing discreet activities on individual assets in isolated life-cycle stages (IAM, 2015).

In order to align the various asset management standards, models, principles and best practices from around the World, the GFMAM (Global Forum on Maintenance and Asset management) produced The Asset Management Landscape. It defines six Asset management subject groups, further divided into thirty-nine subjects (GFMAM, 2014).

Table 1: Overview of applicable maturity models by key concepts from Zachman's framework

\begin{tabular}{|c|c|c|c|c|c|c|}
\hline & What & How & When & Who & Where & Why \\
\hline CMMI & $\mathbf{x}$ & $\mathbf{x}$ & & $\mathbf{x}$ & & \\
\hline UK BIM maturity levels & $\mathbf{x}$ & $\mathbf{x}$ & & & & $\mathbf{x}$ \\
\hline Forrester DMM 4.0 & $\mathbf{x}$ & & & & & \\
\hline Smart Cities MM & $\mathbf{x}$ & & & & & \\
\hline Regulatory Compliance MM & $\mathbf{x}$ & $\mathbf{x}$ & & $\mathbf{x}$ & & \\
\hline Plant Asset Management MM & $\mathbf{x}$ & $\mathbf{x}$ & & & & \\
\hline
\end{tabular}


These represent a comprehensive view of the asset management landscape and are used as a basis for the development of various models and best practices in the field of Asset management. The document helps to compare, and align asset management knowledge and practices.

The GFMAM defines asset management maturity as the '...extent to which the capabilities, performance and ongoing assurance of an organisation are fit to meet the current and future needs of its stakeholders, including the ability of an organisation to foresee and respond to its operating context.' (GFMAM, 2015). Based on this, asset management organisations would benefit greatly from not only achieving the requirements described in the ISO 55000 series, but developing their maturity beyond compliance. In order to help various asset management organisations develop their maturity models, the GFMAM's position statement document defines the key principles for achieving this task.

The Institute of Asset management (IAM) in the UK has developed a number of maturity models over the years (IAM, 2016) based on at-the-time, latest best practice, and newest standards. The latest one is based on the ISO 5500x series of standards and the framework described in the Asset Management Landscape (IAM, 2016). It recognises the fact that the subject of asset management and the characteristics of adequacy and best practice are continually evolving and also the fact there are different operational environments, constraints, cultures and opportunities in asset management, which all affect what is considered competent or excellent.

An integrated maturity model of asset management capabilities (Mahmood et al, 2015) has researched the gaps in terms of key process areas by comparing six existing asset management maturity models against the five dimensions of engineering asset management and suggested an integrated approach. The Australian Asset Institute has built on that research by creating the Asset Management Capability Maturity Model AMCaMM in three steps - identification of key process areas, definition of capability and maturity levels, and the definition of the capability indicators for each capability level for each process area.

\section{Smart Asset Management Maturity (SAMM)}

The definition of 'Smart Asset Management' (SAM) hasn't yet been agreed, but reviewed literature suggests there are a number of characteristics which relate to SAM. These characteristics are: Being able to retrieve required information directly from the asset, be that the asset's unique identifying name or its operational condition; and the communication between the asset and the central intelligent database thereby interacting with the organisational decision making (Nel and Jooste, 2016). The concept of SAM therefore combines the field of asset management, technology management, and organisational decisionmaking (see also Table 2). The mind-shift in asset management is essential: from a reactive approach to a proactive approach. The greatest feature of SAM is therefore the ability to interpret asset data in real time.

Therefore, to be able to better understand what smart asset management might look like, research on similar applications must be conducted. An area which might help in the clarification of different aspects of what is meant by "smart" in smart asset management, are smart (and digital) cities. (Cocchia, 2014) discovered digital cities are much better defined, as compared to smart cities, as all definitions focus on the key role of ICT in improving the quality of services and information supplied to citizens. The purpose of smart cities is often much broader, as they focus on outcomes, such as the improvement in the quality of urban life defined by the environmental, economic and social requirements, underpinned by the role of innovation and technology. Lately, ICTs have become a large part of smart cities and, therefore, digital cities are becoming a subset of smart cities. In the smart factory context, the term "smart" is defined as having access and making decisions based on real-time data (Shariatzadeh et al, 2016).

Four dimensions have been identified that determine digital maturity (Gill and Van Boskirk, 2016) culture, technology, organisation, and insights. Besides the people (culture), process (organisation), and technologies, it is the information and the insights that can subsequently be gained which is one of the dimensions. Information is the lifeblood of any form of asset management.

Table 2: Review of smart asset management development concepts: derived from (ICE, 2018)

\begin{tabular}{llllll}
\hline Customers & Leadership & Commercial & Capability & $\begin{array}{l}\text { Asset } \\
\text { delivery }\end{array}$ & $\begin{array}{l}\text { Asset } \\
\text { management }\end{array}$ \\
\hline insight & strategy & definition & skills & availability & $\begin{array}{l}\text { information } \\
\text { management }\end{array}$ \\
participation & culture & recognition & suppliers & $\begin{array}{l}\text { Information } \\
\text { management }\end{array}$ & making sense \\
experience & innovation & $\begin{array}{l}\text { digitisation } \\
\text { investments }\end{array}$ & $\begin{array}{l}\text { information } \\
\text { security }\end{array}$ & $\begin{array}{l}\text { standards and } \\
\text { automation }\end{array}$ & decision making \\
\hline
\end{tabular}


It is the information that forms the basis for decisions thereby helping asset management organisations gain value from their assets. Smart asset management enables the asset management organisations to make better decisions by taking advantage of processes enabled by the latest technologies, to operate with the information which is the latest, true, and trusted information; and enriched through various procedures. BIM ensures integrity and prevents the loss of information created and collated during an asset's lifecycle. The more efficiently information about our assets is integrated, the higher may be the value extracted from those assets. At the moment, information integration is done on ad-hoc basis and is centred around individual integration opportunities (Kang, O’Brien and O'Connor, 2014).

A maturity model for information integration of capital projects has been created in order to address those issues. Similarly, at the heart of smart cities is a simple process, focused around data: improved data capture advanced data processing \& analysis - improved visualisation \& display of data - targeted, automated, dynamic response - improved efficiency \& better outcomes (Scottish cities alliance, 2014). Besides data, the maturity of smart cities is considered across strategic intent, technology, governance \& service delivery models and stakeholder management.

Study of maturity models in relation to information systems, (Proenca and Borbinha, 2016) identified a several models, that were compared by structure, process and the support they offer. The availability, integrity and transfer of data and information during the asset's life-cycle are important factors to consider which areas BIM maturity models consider (Succar, Sher and Williams, 2013). Other digital maturity models have been created for other industries (Gill and VanBoskirk, 2016), (Aleem, Capretz and Ahmed, 2016), (Paavel, Karjust and Majak, 2017).

\section{Digital Built Environment Maturity Model}

The purpose of the Digital Built Environment Maturity Model (dbEMM) is a model that can be used to assess the level of digital capability of asset management organisations.

dbEMM is illustrated as a three-dimensional cuboid in which sides represent various criteria which need to be evaluated at each maturity stage (Figure 2):

- Areas of Digital Capability (ADC) [red]

- Supporting Organisational Environment (SOE) [green]

- Digital Twin Maturity Stages (DMS) [blue]

ADC (red), includes three main areas (data management, data analysis and decision making) which determine the digital maturity.

Note, data management covers whole data-lifecycle from data acquisition to storage and processing, while analysis prepares data for decision making.

SOE (green), represents three systems (people, process and technologies). An organisation may find its ADCs at different stages. However, the organisation can progresses from one stage to the next if requirements for current stage have been successfully evaluated.

Whilst the greatest value may be created if the digital capability is standardised across the whole organisation, sometimes that is not feasible.

Consequently, the sub-organisations, as part of the bigger organisation, may be evaluated on their own, using the dbEMM. In such cases the term "organisation" used in the dbEMM, should be replaced by, and understood as, the term "Sub-organisation".
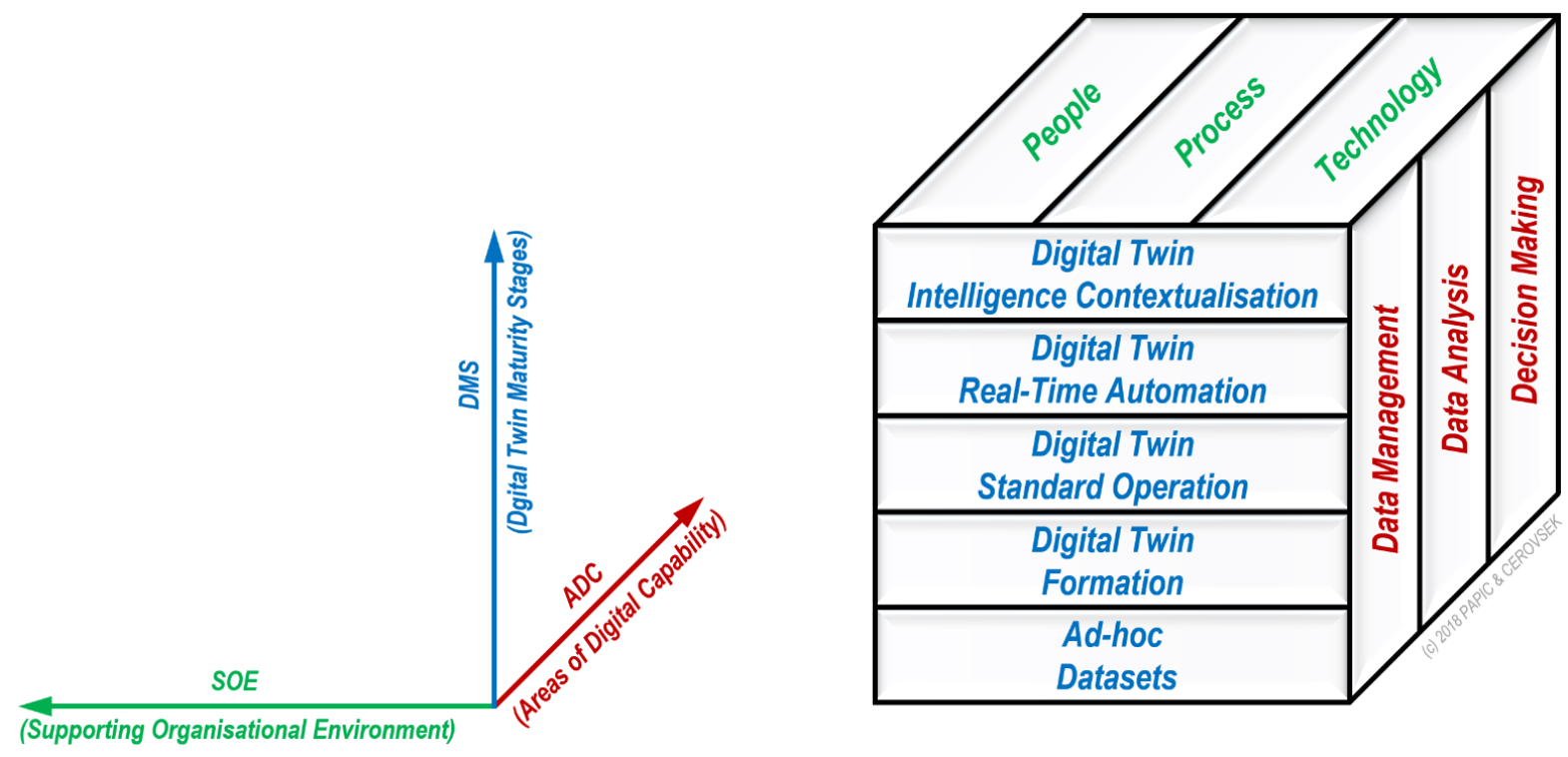

Figure 2: Digital Built Environment Maturity Model (dbEMM) - 'Digital Twin Maturity' 
At each stage, the lower level elements get evaluated to see if they are still needed and, if they are, do they need to be adjusted or changed, or kept as they are?

Some elements of the ADCs of the more mature stages may be implemented at lower levels of maturity then defined in the model. However, dbEMM can assist organisations in levelling up its maturity in a structured and comprehensive way.

The supporting organisational environment, established roles, responsibilities and procedures must be evaluated for each Area of Digital Capability that are specific to five digital twin maturity stages:

- Ad-hoc Datasets.

- Digital Twin Formation.

- Digital Twin Standard Operation.

- Digital Twin Real-Time Automation.

- Digital Twin Intelligence Contextualisation.

\section{Stage 1: Ad-hoc Datasets.}

At this stage the organisation has no standardised, organisation-wide defined digital capability. Data is collected either on paper or digital format and stored in ad-hoc repositories. The level of management of said data is, at best, local (a single person, or group).

Data is used for single-use cases, and is rarely re-used, as it usually gets lost, is not shared, becomes obsolete, or is not trusted.

Combining different pieces of data to create new uses for it, or to learn more from it, is rare and depends on the user's experience, or technology point-solutions. However, if at some point in the future, the organisation decides to carry out an organisation-wide standardisation of its digital capability it must be evaluated starting at the 1 st stage of the dbEMM.

\section{Stage 2: Digital Twin Formation.}

At this stage the organisation defines and forms the first Digital Twin. The business outcomes and functions its digital capability needs to support are defined. Processes, workflows, and data flows get mapped, information requirements, inputs and outputs, information structures, standards, and roles \& responsibilities get defined. The Digital Twin is defined and built.

Data gets collected, managed, and used in the same manner as in Stage 1. Data, which already exists in a digital format in various, ad-hoc repositories, gets transferred into the new, organisation-wide repository, popularly called the Single Source of Truth for the organisation.

The level of data management is organisation wide. The data collected in the Digital Twin is still in a "preproduction" state.

\section{Stage 3: Digital Twin Standard Operation.}

At this stage the organisation introduces the Digital Twin into operations. It populates their Digital Twin with all the newly created data about their assets, as defined in their information requirements. The collection of historic data, may not exist yet or may be available on paper, gets defined and the data is progressively collected, depending on the business need. New business cases get defined, based on the digital capability. The Digital Twin must be kept insynchronisation with reality. However, this is not yet done in real-time, but at pre-defined intervals, points in time, or based on events.

Data is collected in a digital format and stored in the defined repository. The level of data management is organisation wide. Data is used for multiple-use cases and is often re-used, as it is accessible in a single place to anyone with access rights. Various types of data get combined and provide more insight, thus allowing for better decision making. $3^{\text {rd }}$ party data is used to provide more insights, potentially in combination with the organisation's own data.

\section{Stage 4: Digital Twin Real-Time Automation.}

At this stage the organisation introduces the elements of the Internet of Things into operations. Some of the data about their assets gets collected, transmitted, stored, and/or used almost instantly after an event's occurrence.

Data is collected in digital format and stored in the defined repository. The level of data management is organisation wide. Data is used for multiple-use cases and is often re-used, as it is accessible in a single place to anyone with access rights. Various types of data get combined and provide more insight, and thus allow for better decision making. $3^{\text {rd }}$ party data, including the end users real-time data, is used to provide more insights, potentially in combination with the organisation's own data. As some of the data is collected in real time and, potentially, continuously, some decisions can be taken much faster. The Digital Twin is more in-sync with reality using sensory reality capturing.

\section{Stage 5: Digital Twin Intelligence Contextualisation.}

At this stage the organisation introduces elements of Artificial Intelligence (AI) systems into operations. Some of the assets are capable of influencing decisions related to them.

Data is collected from various sources, across project phases - eg above the built environment (satellite LIDAR), from the built environment (temperature, stress, vibrations), mobile assets (UAV) and artificial intelligence allowing for cross-functional autonomous decision making in a given context. 


\section{Discussion and conclusions}

The critique of the model could be eventual confusion about processes that are put in two dimensions. First, a process appears in the organisational triad (people, process, technology) and second, processes appear in the areas of digital capability (data management, data analysis and decision making).

In order to properly interpret the dbEMM, process in the triad should be understood as actual process in a specific organisational context - to deliver required outcomes by digital capabilities. Due to the limited scope of this paper, possible applications of dbEMM cannot be demonstrated in more detail. However, it can be claimed that the proposed maturity model could be successfully applied in many different contexts.

The initial response to maturity model shows that it may become a valuable tool to streamline the development of smart asset management and a digital (twin) - built environment. The concept of Digital Twin Maturity might be also transferred to other application areas/industries.

\section{References}

Aleem, S., Capretz, L.F. and Ahmed, F. (2016). Empirical investigation of key business factors for digital game performance. Entertainment Computing, 13, pp.25-36.

Bentley, G. (2018). Going digital to advance infrastructure delivery: The open information project. Voices on infrastructure: Harnessing the promise of digital. Global Infrastructure Initiative, March 2018, McKinsey \& Company, pp. 04-08.

Brumby, J., Verhoeven, M. 2010. Public Expenditure after the Global Financial Crisis. V: Canuto, O. (ed.), Giugale, M. (ed.). The day after tomorrow. A Handbook on the Future of Economic Policy in the Developing World. Washington, D.C, The World Bank: p.193-206. https://openknowledge.worldbank.org/bitstream/h andle/10986/2507/567990PUB0The010Box35373 9B01PUBLIC1.pdf?sequence=1 (Acquired 11.09.2017)

Cabinet Office (2011). Government Construction Strategy. UK Government publication available at: https://www.gov.uk/government/publications/gov ernment-construction-strategy

CMMI Product Team. 2010. CMMI for Development. Improving processes for developing better products and services, ver. 1.3. Pittsburgh, Carnegie Mellon University, Software Engineering Institute: $468 \mathrm{p}$.

Cocchia, A. 2014. Smart and Digital City: A Systematic Literature Review. In: Dameri, R. P. (ed.), Rosenthal-Sabroux, C. (ed.). Smart City.
How to Create Public and Economic Value with High Technology in Urban Space. Cham, Heidelberg, New York, Dordrecht, London, Springer Intl. Publishing Switzerland: p. 13-43.

Fraser, P.; Moultrie, J. \& Gregory, M. (2002). “The use of maturity models/grids as a tool in assessing product development capability: A review". IEEE International Engineering Management Conference, Cambridge.

GFMAM. 2014. The Asset Management Landscape. 2nd ed. Global Forum on Maintenance \& Asset Management: 57

p. http://www.gfmam.org/files/isbn978_0_9871799_ 2_0_gfmamlandscape_secondedition_english.pdf (Acquired 27.12.2018)

GFMAM. 2015. Asset Management Maturity. A Position Statement. 1st ed. Global Forum on Maintenance \& Asset Management: 11 p. ISBN_978-0-9870602-4-2 Gill, M. and VanBoskirk, S. (2016). Digital Maturity Model 4.0. Benchmarks: Digital Transformation Playbook.

IAM. 2015. Asset Management - an anatomy. Ver. 3. The Institute of Asset Management: $83 \mathrm{p}$. https://theiam.org/knowledge/KnowledgeBase/the-anatomy/ (Acquired 27.12.2018)

IAM. 2016. Asset Management Maturity Scale and Guidance. The Institute of Asset Mngt: 99 p. https://theiam.org/knowledge/KnowledgeBase/asset-management-maturity-scale-andguidance/ (Acquired 27.12.2018)

ICE, ICG, MOTT MACDONALD. 2018. Ripe for transformation, ready for change?: $28 \mathrm{p}$. http://www.p13.org.uk/wpcontent/uploads/2018/07/Ripe-for-transformationready-for-change.pdf (Acquired 27.12.2018)

ISO 55000:2014(E). Asset management - Overview, principles and terminology.

Kang, Y., O’Brien, W. J., O’Connor, J. T. 2014. Information-Integration Maturity Model for the Capital Projects Industry. Journal of Management in Engineering 31, 4: 1-12.

Mahmood, M.N., Dhakal, S., Wiewiora, A., Brown, K. and Keast, R. (2015). A comparative study on asset management capability maturity models. International Journal of Strategic Engineering Asset Management, 2(4), pp.328-347.

Nel, C.B.H. and Jooste, J.L. (2016). A technologicallydriven asset management approach to managing physical assets-a literature review and research agenda for 'smart 'asset management. South African Journal of Industrial Engineering, 27(4), pp.50-65. 
O’Kane, T., Casserly, T., McCartney, P. 2015. The Regulatory Compliance Maturity Model (RMM) for Anti-Money Laundering (AML). Government Risk \& Compliance Technology Centre: 2 p. http://www.grctc.com/wpcontent/uploads/2015/12/The-RegulatoryCompliance-Maturity-Model-RMM-for-AntiMoney-Laundering-AML.pdf (Acquired 11.09.2017)

Paavel, M., Karjust, K. and Majak, J. (2017). Development of a product lifecycle management model based on the fuzzy analytic hierarchy process. Proceedings of the Estonian Academy of Sciences, 66(3), pp.279-287.

Popper, N., Gates, G. 2016. Rebuilding Our Infrastructure. The New York Times. https://www.nytimes.com/interactive/2016/11/15/ business/dealbook/dealbook-

infrastructure.html?partner=IFTTT (Acquired 11.09.2017)

Proença, D. and Borbinha, J. (2016). Maturity models for information systems-A state of the art. Procedia Computer Science, 100, pp.1042-1049.

Paulk, M. C., Curtis, B., Chrissis, M. B., \& Weber, C. V. (1993). Capability maturity model, version 1.1 . Software, IEEE, 10(4), 18-27.

Scottish cities alliance, Urban Tide. 2014. Smart Cities Maturity Model and Self-Assessment Tool. Guidance Note for completion of Self-Assessment Tool. Scottish cities alliance: 42 p. https://www.scottishcities.org.uk/site/assets/files/ 1103/smart_cities_readiness_assessment__guidance_note.pdf (Acquired 27.12.2018)

Shariatzadeh, N., Lundholm, T., Lindberg, L. and Sivard, G. (2016). Integration of digital factory with smart factory based on Internet of Things. Procedia CIRP, 50, pp. 512-517.

Succar, B., Sher, W. and Williams, A. (2012). Measuring BIM performance: Five metrics. Architectural Engineering and Design Management, 8(2), pp.120-142.

Zachman, J.A., 1987. A framework for information systems architecture. IBM systems journal, 26(3), pp.276-292. 